\title{
Users' Emotional Attachments to Internet Celebrities: Based on the Perspective of Extended-self
}

\author{
Pei-Shan Hsieh \\ Tunghai University \\ psh1983@thu.edu.tw
}

\author{
Junmin Ou \\ Shenzhen University \\ 695037325@qq.com
}

\author{
Jialin $\mathrm{Xu}$ \\ Shenzhen University \\ 616954831@qq.com
}

\begin{abstract}
Although previous researcher has focused on the use of social media between celebrities and fans from the use and gratification perspective, knowledge on why users stick with live streaming is limited. Therefore, the authors propose that sticking with live streaming reflects a strong connection between celebrities and users. We define emotional attachment as the strength of the cognitive and emotional bond connecting the celebrities with the self. Consequently, in this study, we adopt attachment theory to investigate users, tendency to stick with live streaming from the extended-self perspective. The findings of this study fully support the hypotheses specifying the relationships between constructs. Emotional attachment was influenced by gratifying the self, enriching the self and enabling the self, and which in turn are strong predictors of users' stickiness intention. The current research contributes to the further expansion of social media research and applied attachment theory into the live streaming context.
\end{abstract}

\section{Introduction}

Live streaming refers to internet content delivered in real time, which means users can upload videos and others can watch these immediately. Growing rapidly over the past five years, the live-streaming industry has become a viable source of income for many thousands across the globe, but nowhere is it more lucrative than in China. In 2016, according to The Chinese Live Streaming Report, live streaming is becoming the most popular video format with more than 325 million online viewers in total, or $45.8 \%$ of Chinese citizens. The revenue in live streaming is increasing along with its popularity and it's predicted to be a US $\$ 5$ billion market by the end of 2017 according to Credit Suisse [56].

Most previous studies on live streaming are related to the technical aspect, such as peerto peer-transport. For example, Rodriguez-Gil et al. [1] explore how to provide web-based interactive live-streaming, and Tran, Won, and Kim [2] proposed a methodology for a peer-topeer video live streaming system on mobile broadcasting social media. In the last few years, some research has been carried out exploring user behavior and social media or live streaming. For example, social media between celebrities and fans from the use and gratification perspectives [3], and Kim and Song [4] recently investigated how the selfdisclosure of celebrities on their personal social media accounts affects fan perceptions. Moreover, Payne et al. [5] examined the learning effects of live streaming video game instruction over twitch. Scheibe et al. [59] analyzed information production as well as information reception behavior. Haimson and Tang examined how people currently experience events using Facebook Live, Periscope, and Snapchat Live Stories [60].

In the process of live streaming, users can choose over 200 live streaming platforms which are focusing on different markets and viewers - such as gamers, fashionistas, ecommerce, etc. Some users, however, "stick" to a specific live streaming platform, whether from emotional attachment to the internet celebrity. Hu et al. [34] and Zhao et al. [61] examined the stickiness of audiences on live video streaming platforms. Therefore, the authors focus that sticking with live streaming reflects a strong connection between internet celebrities and users, because the internet celebrity is part of a user's self-conception. Attachment theory in psychology and marketing suggests that attachments can extend beyond person-to-person relationship contexts to celebrities [6]. An attachment object becomes connected to the self when it is included as part of the user's self-concept. Further, the self-concept is generally described as the collection of characteristics, traits, and memberships that cognitively represent an individual in memory [7]. Moreover, people are most likely to develop attachments to offerings that fulfill their functional needs (enabling the self), their experiential needs (gratifying the self), and their emotional needs (enriching the self) [8]. Building from these three needs, we 
recognize antecedents that constitute suitable strategies for enhancing the internet celebrityself connection and consequently user's emotional attachment to internet celebrity.

Consequently, in this study, we adopt attachment theory to investigate users' tendency to stick with live streaming from the self-concept perspective. Overall, we seek to address the following questions:

1. What kinds of needs can explain users' propensity to stick with live streaming celebrities?

2. How does self-concept influence stickiness intention through emotional attachment?

Contributing to the emerging discussion on the issues of live streaming, this research investigates users' needs and emotional attachment respond to why people stick with live streaming. This study examines users' stickiness intention from the attachment theory. We also investigate enabling the self, gratifying the self, enriching the self and explore emotional attachment, as well as analyze the effects of these variables on users' stickiness intention.

\section{Theoretical background}

\subsection{Attachment theory}

Attachment theory was conducted by British psychiatrist Bowlby [9]. The theory is generally defined as a special relationship between infants and their caregivers (basic is the mother). Robert [10] defined attachment in psychology as an emotional connection between people, a feeling of dependence, and people seek emotional comfort through mutual dependence. Lopez [11] believed that attachment is a strong and permanent emotional connection between individual and specific person, is the emotional connect formed after individual feeling sense of close and security. Research in the field of psychology has focused on interpersonal attachment, and related studies have shown that international attachment can also be extended to situations expect interpersonal relationships, which is person's attachment. And the object of person's attachment can be real objects or virtual objects.

Many marketing research shows that consumers will not only produce attachment to possessions [12], and there will be place attachment [13], product attachment [6], brand attachment [14], etc. Ball and Tasaki [12] argue that attachment is the degree which consumers support their self-concept through what they once had, what they have, or what they want to have. Consumers can know about themselves, define themselves through the product they bought. Furthermore, they can build a sense of belonging and then support and enhance selfconcept. Some scholars believe that the relationship between brand or product and selfestablishment plays a key role in the formation of emotional attachment of consumers [8]. After purchasing product, through individual level and social level of self-support and associated self-concept, consumers make goods or brand become extension of self, and form emotional attachment for goods or brand.

In the virtual world, the attachment theory is implied in analyzing the online relationship. Recent research of online community found that identity-based attachment and bond-based attachment will enhance willing to help the group or individual. In addition, these two attachments also strengthen participation and retention, which is mediated by attachment to the community [15]. Thus, the emotional attachment can be extended to online situation.

To sum up, the consumer emotional attachment expressed by scholars is a kind of emotional connection between consumers and products, services or brands, which can occur in online and offline situation. What do consumers seek for to support self-concept? Emotional attachment is formed by connection of self and self-satisfaction from possessions, which means that the extension of the self is the key to form an attachment. In live streaming, the internet celebrity does not refer to wellknown people on the internet such as the traditional Youtubers, who record their video and then upload to the website. Instead, this concept specially refers to the streamers, who are the content providers on the live streaming platforms. For example, in 2013, approximately one million game streamers on the largest live streaming platform Twitch broadcasted the process of playing games, attracting more than 40 million audiences. Due to the popularity of the streamers, they become celebrities on not only the platform but also the internet. In this article, emotional attachment is a mediator, which mediates the inner feeling (extended-self) and the behavioral intention (users' stickiness).

\subsection{Extended-self}

Baumeister [58] conducted a study of selfconcept and laid the foundations for modern conceptions of self, defined the self-concept as "self becomes a person through perception, feeling and thinking." He proposed an idea to separate self into two kinds as well. One is experience and the other is pure self. 
At the same time, James [57] stated that the boundary of self-experience and pure self is indistinct. It is clear that between what a person calls me and what he simply calls mine is difficult to be distinguished. In addition, he held that a person's self is the sum of all that he can call his, not only his body and his psychic powers, but his clothes and his house, his wife and children, his ancestors and friends.

The self-concept stated that people have intrinsic motivation to extend themselves and expect to contain the external things into their self-concept. In 1988, Belk renewed the concept and published that a person's self can be extended by objects in his possession [16]. The article posited an individual self with an inner core self as well as aggregate selves ranging from family to neighborhood to nation. Enhancing these self-constructions are various possessions, which are regarded by their owners as having different degrees of centrality to one or more of their individual or aggregate senses of self. The original article [16] also detailed various evidence that objects form a part of extended self; specified processes by which objects are cathected as a part of self.

First, extended-self applied in consumer behavior, and further Sivadas and Venkatesh [17] proposed that consumers can cultivate their extended-self by confirming and owning objects. Possessing showed a relationship with forming attachment. Hamilton and Hassan [18] pointed out that consumers treat possession as a status symbol in order to integrate into a group. Some researchers showed a fact that by categorizing the brand as part of the self, a consumer develops a sense of oneness with the brand, establishing cognitive links that connect the brand with the self [14]. Self-extended concept [19] posits that people possess an inherent motivation for self-expansion, or a desire to incorporate others (here brands or products) into their conception of "self." The more an entity (brand or product) is included in the self, the closer is the bond that connects them. The more attached a person is to the brand, the more likely he or she is to move from an egocentric to a more reciprocal brand relationship that involves sharing resources with the brand. As such, consumers who are highly attached to a brand should treat the brand preferentially and engage in restorative behaviors that ensure brand relationship continuation [20].

Park et al. [8] indicate that people are most likely to develop attachments to offerings that fulfill their experiential needs (gratifying the self), their emotional needs (enriching the self), and their functional needs (enabling the self). Building from these three users' needs, we recognize antecedents that constitute suitable strategies for enhancing the internet celebrity self connection and consequently user- internet celebrity emotional attachment. We posit that: gratifying the self (GS) which means interpersonal likeability and content enjoyment are factors that gratify a user's self; selfexpression and virtual community identity are factors that enrich the self (ENRI); a sense of an efficacious and capable self are factors that enable a user's self (ENAB).

At a background of digital time, Bolter [21] found that extended-self or individuals' possession can include head portraits, words information, photos, videos and other else on game websites and social networking. Belk [22] indicated extended-self update dues to dematerialization, reembodiment, sharing, broadly co-construction of self and collective memory. With the development of net data called web 2.0, users contributing on context has become a kind of extended-self. And it draws a positive influence on continuous using and loyalty among users, which means the users' attachment is enhanced [23]. To sum up, extended-self is the key to form emotional attachment and users' attachment will be positively affected.

\subsection{Stickiness intention}

Previous definitions of web site stickiness focus on the business side [24] which is based on Oliver's definition of customer loyalty [25]. From the user's side, "stickiness" can be defined as repetitive visit and use of a preferred web site because of a deeply held commitment to reuse the web site consistently in the future, despite situational influences and marketing efforts that have the potential to cause switching behavior. Lin [26] also described that stickiness implicates an ability of websites to keep users staying and repeating purchasing behavior. The definition presented here can be thought of as using a live streaming platform in a user's normal activity or embedding a mobile phone within a user's routine, which is similar to the notion of continuous use. In addition, the research shows that consumers can stick to collectibles [29], places of residence [30], brands [31], other types of special or favorite objects [32] and celebrities [33].

In the present study, in the context of live streaming platform continuous using, stickiness intention is a measure of an individual's intention to stick to (i.e., use) a live streaming platform on a regular basis without stopping in the near future. 


\section{Research model and hypotheses}

Overall, we adopt attachment theory as the theoretical basis and focuses on extendedself perceptive in emotional attachment and users' stickiness intention. As shown in Figure 1 , we consider that users are most likely to develop attachments to offerings that fulfill their experiential needs (gratifying the self), their emotional needs (enriching the self), and functional needs (enabling the self). Building from these three needs, we posit that selfexpression is the main factor that enriches a user's self, and gratifying the self, enriching the self, and enabling the self are important antecedents of emotional attachment and stickiness intention in the context of live streaming.

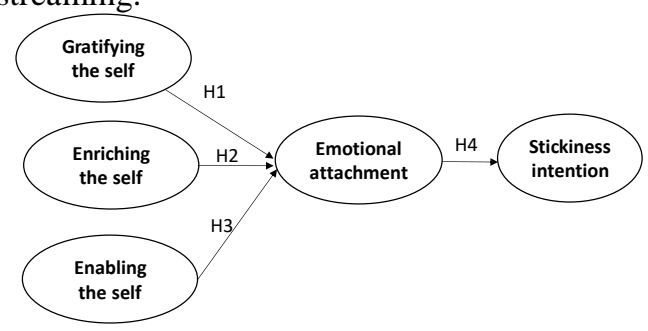

Figure 1. Research model

\subsection{Gratifying the self and its impacts on emotional attachment}

According to a psychology study, positive and pleasure emotion can effectively promote the brain activities related to emotional attachment, which can weaken social distance and strengthen close relationship [35]. Explored by Chaudhuri and Holbrook [36], hedonistic goods will make consumer have pleasure feeling and positive emotional reaction, which helps to create emotional connection between consumer and brand. Similarly, by empirical study of Carroll and Ahuvia [37], hedonistic good have positive effect on the formation of attachment to brand. The self-mission corresponding to extendedself is pleasuring and gaining positive emotion proposed by Breckler and Greenwald [38]. Furthermore, the formation of self-concept can promote the formation of attachment effectively. Under the background of live streaming, audience watching live streaming is regarded as consumer and the content in live streaming is regarded as good. Thus, by enjoying the hedonistic function in live streaming, it is possible for audience to form emotional attachment to the live streaming platform. Accordingly, we propose the following hypothesis:
H1. Gratifying the self has positive effects on the formation of emotional attachment with internet celebrities.

\subsection{Enriching the self and its impacts on emotional attachment}

Enriching the self describes the process that emotional connection is formed to specific object which can symbolically representing one's past self, which includes one's origin, history and core self, his present self, which includes who the person is and what he believes, or his future self, which who one wants to be [39]. Similarly, Carroll and Ahuvia [37] regarded self-expression as consumer's perception of the degree to which the specific retailer enhances one's social self and/or reflects one's inner self. These two concepts both reveal that one's self, concluding experience, expectation, characteristic and so on, can be extended to other entities. After perceiving themselves, consumer will find definition of themselves and thus prefer the goods which are more consistent to themselves, with the purpose of expression themselves through the goods [16]. In addition, people tend to form strong emotional attachment to those goods that can show their personality and display their position [40].

Ball and Tasaki [12] explored that selfmission corresponding to public self is selfexpression, which has influence on formation of emotional attachment. Belk [16] revealed that the need of self-expression can be fulfilled by consumption, on account of that the good or service purchased by consumer represent themselves to some extent. Furthermore, Park [8] explored that enriching the self will strengthen the brand attachment and then enhance brand commitment, which will cause positive actual behavior at specific object.

Live streaming is a highly interactive activity, which allow all the audiences to express their idea freely, safely and equally by using the bullet screen. It is a chance to show their value, share their past experience, even their expectation of the internet celebrity or the content, which are part of themselves. Additionally, internet celebrities always reply audiences by the bullet screen to show their kindness, and encourage audiences to express themselves. Through interaction with the internet celebrity and other audiences, audiences enrich themselves and probably form emotional connection to live streaming platform. Accordingly, we hypothesize the following: 
H2. Enriching the self has positive effects on the formation of emotional attachment with internet celebrities.

\subsection{Enabling the self and its impacts on emotional attachment}

In the field of consumer behavior research, Ball and Tasaki [12] revealed that individual can enable himself by purchasing good or service, which will promote the formation of emotional attachment to brand. The reliability of good can provide consumer sense of safety, owing to that the function of good can help consumer to solve problem, which makes them think their ability is strengthened and extended. By this way, consumers are more satisfied themselves and enable themselves [6]. Through watching live streaming, users can learn many skills from internet celebrities, such as dancing, singing and cooking. Furthermore, in some live streaming platforms, users can find professionals who teach finance, math, language so that they can enhance their ability to deal with problems, which make them regard live streaming help them to achieve their goal. Through enabling the self, they possibly form emotional attachment to live streaming platform. Accordingly, we test the following hypotheses:

H3. Enabling the self has positive effects on the formation of emotional attachment with internet celebrities.

\subsection{Emotional attachment toward stickiness intention}

Although attachment theory was initially applied in kid and mother relationship, in field of psychology, recent researches have revealed that customers can form attachment to other entities in marketing, such as product brands [41], celebrities [6], and special possessions [42]. Under the background of sport, previous research has explored a direct relationship between loyalty and reasons for liking a particular sport team. In Funk and James [43] research, they found that in the process of a fan changing his attitude from 'attracted by a sports team' to 'loyalty to a sports team', attachment plays a mediating role. Additionally, a research by Lee, Kyle and Scott [44] also reveals the role of place attachment as a mediator of the relationship between visitors' positive evaluation of their festival experience and their loyalty to the host destination.

When implied in the field of internet, Zott defined users' stickiness as the ability of website or other entities to attract and keep visitors [45]. Particularly for profit organization, Khalifa et al. [46] proposed that stickiness which is to motivate customer to consume on website for a long period. Similarly, loyal user focus on continued use on specific objectives [47]. Therefore, emotional attachment to the live streaming may also have positive effect on the loyalty, which is closely related to the concept of user's stickiness intention.

H4. The emotional attachment with internet celebrities has positive effects on user's stickiness intention to the live streaming.

\subsection{Mediation effects}

In previous studies of consumer behavior research, emotional attachment is always regarded as a significant mediator between extended-self and consumer behavior. Park [8] revealed that enabling, enriching and gratifying the self can enhance the brand-self connection. Therefore, the brand commitment, which means behavioral intention to maintain the relationship with a brand, will be strengthen and consumers will continue purchase good or service. Additionally, explored by Vlachos et al. [48], self-expression and gratification have positive effect on consumer loyalty, which is mediated by emotional attachment. By reviewing these researches, emotional attachment mediates the relationship between extended-self and continued use. Under background of live streaming, the behavior of watching live streaming is similar to the use of service. Furthermore, the inner content of selfextension is resemblance, such as pleasuredself and gratifying the self, realized-self and enabling the self. As mentioned before, concept of users' stickiness contains continued use. Thus, it is possible that this mediating rule can also be implied in live streaming. Formally, we test the following hypotheses:

H5a. Emotional attachment mediates the relationship between gratifying the self and users' stickiness intention.

H5b. Emotional attachment mediates the relationship between enabling the self and users' stickiness intention.

H5c. Emotional attachment mediates the relationship between gratifying the self and users' stickiness intention.

\section{Study design and data collection}

We measured gratifying the self and enriching the self each with three items and two items adapted from Vlachos et al. [48]. Three question items of enabling the self was adopted 
from Thomsom [6]. As for the mediator variable, we measured emotional attachment with three items from Park et al. [14]. We operationalized stickiness intention using three items from Li, Browne, and Wetherbe [49], Agarwal and Karahanna [28]. In Table 1, we list all the items used in our study.

All question items used a 5-point Likert scale, with 1 denoting "strongly disagree" and 5 denoting "strongly agree." We also collected personal information including age, gender, frequency of watching live streaming, type of live streaming they watch the most.

We performed a pilot study that involved 40 students randomly selected from the university, and used their responses to assess the reliability and convergent and discriminant validity of the items, as well as to fine-tune our survey design and data collection procedure. The results of the pilot data were satisfactory, suggesting that the items exhibit appropriate reliability, and convergent and discriminant validity. On average, students completed the survey in 7.5 minutes, which helped us to estimate the time requirement in the subsequent formal test.
In the formal test, the questionnaires were distributed online via a data collection tool, and offline via physical copies for two weeks. Subjects interacted with the questionnaire web page as follows.

First, the introductory page was presented to a subject. The subject was instructed that the purpose of this study was to explore a users' stickiness intention of live streaming. To confirm a subject who has experiences about watching live streaming, we encouraged subjects to provide their e-mail addresses to enroll in a lucky draw after completing the survey. In addition, we also approached students in the class for their voluntary participation. Following a study protocol and using a script, an investigator briefed students on our study, explained how we would use and protect the collected data, and solicited their participation. In particular, the investigator assured data security and confidentiality, indicated our analysis would not rely on any personally identifiable data, and explicitly addressed any concerns related to privacy.

Table 1. Measured items

\begin{tabular}{|c|c|c|c|}
\hline Construct & \multicolumn{2}{|l|}{ Items } & References \\
\hline \multirow{3}{*}{$\begin{array}{l}\text { Gratifying } \\
\text { the self } \\
\text { (GS) }\end{array}$} & GS-1 & I feel pleasant by watching live streaming. & \multirow{3}{*}{$\begin{array}{l}\text { Vlachos et al. } \\
\text { [48] }\end{array}$} \\
\hline & GS-2 & $\begin{array}{l}\text { I feel watching live streaming makes my life more } \\
\text { colorful. }\end{array}$ & \\
\hline & GS-3 & $\begin{array}{l}\text { I feel time passes quickly when watching live } \\
\text { streaming. }\end{array}$ & \\
\hline \multirow{2}{*}{$\begin{array}{l}\text { Enriching } \\
\text { the self } \\
\text { (ENRI) }\end{array}$} & $\begin{array}{l}\text { ENRI- } \\
1\end{array}$ & $\begin{array}{l}\text { Interaction with the internet celebrity and other } \\
\text { audiences, I express who I am. }\end{array}$ & \multirow[t]{2}{*}{$\begin{array}{l}\text { Vlachos et al. } \\
\text { [48] }\end{array}$} \\
\hline & $\begin{array}{l}\text { ENRI- } \\
2\end{array}$ & $\begin{array}{l}\text { Interaction with the internet celebrity and other } \\
\text { audiences, I reflect my personality. }\end{array}$ & \\
\hline \multirow{3}{*}{$\begin{array}{l}\text { Enabling } \\
\text { the self } \\
\text { (ENAB) }\end{array}$} & $\begin{array}{l}\text { ENAB- } \\
1\end{array}$ & $\begin{array}{l}\text { I can improve some of my ability, such as playing } \\
\text { computer games, making up or singing. }\end{array}$ & \multirow[t]{3}{*}{ Thomsom [6] } \\
\hline & ${ }_{2}^{\text {ENAB- }}$ & $\begin{array}{l}\text { I feel more confident when solving problems by } \\
\text { watching live streaming. }\end{array}$ & \\
\hline & $\begin{array}{l}\text { ENAB- } \\
3\end{array}$ & $\begin{array}{l}\text { I feel more effective and efficient by watching live } \\
\text { streaming. }\end{array}$ & \\
\hline \multirow{3}{*}{$\begin{array}{l}\text { Emotional } \\
\text { attachment } \\
\text { (EA) }\end{array}$} & EA-1 & $\begin{array}{l}\text { My mood is very good when watching live streaming } \\
\text { internet celebrities. }\end{array}$ & \multirow[t]{3}{*}{ Park et al. [14] } \\
\hline & EA-2 & $\begin{array}{l}\text { When people praise or criticize live streaming internet } \\
\text { celebrities, I also feel that I am praised or criticized. }\end{array}$ & \\
\hline & EA-3 & $\begin{array}{l}\text { When watching live streaming, the experience of } \\
\text { internet celebrities or other audiences can make me } \\
\text { think of something relevant. }\end{array}$ & \\
\hline \multirow{3}{*}{$\begin{array}{l}\text { Stickiness } \\
\text { intention } \\
\text { (SI) }\end{array}$} & SI-1 & $\begin{array}{l}\text { I plan to keep using this live streaming platform in the } \\
\text { future. }\end{array}$ & \multirow{3}{*}{$\begin{array}{l}\text { Li, Browne, and } \\
\text { Wetherbe [49]; } \\
\text { Agarwal and } \\
\text { Karahanna [28] }\end{array}$} \\
\hline & SI-2 & $\begin{array}{l}\text { I intend to continue using this live streaming platform } \\
\text { in the future. }\end{array}$ & \\
\hline & SI-3 & $\begin{array}{l}\text { I expect my use of this live streaming platform to } \\
\text { continue in the future. }\end{array}$ & \\
\hline
\end{tabular}

\section{Analyses and results}

We collected 180 responses from a convenience sample of those who agreed to participate. After removing partially completed surveys, we retained 143 data points, representing a $79.4 \%$ effective response rate.
Among the respondents, $67.8 \%$ were female and $32.2 \%$ were male; $7 \%$ of them were under 19 years old, $89.5 \%$ are $20-29$ years old, and $3.5 \%$ are 30-39 years old, because live streaming watch is especially prevalent among young adults. 


\subsection{Validity and reliability}

All scales were tested using exploratory factor analysis (SPSS version 22). We assessed the reliability of our items by examining the Cronbach's Alpha values, which exceeds the common threshold of .70, suggesting adequate reliability [50]. We examined the convergent and discriminant validity by performing a confirmatory factor analysis. The cross-factor loadings are summarized in Table 2. According to the results, items measuring the same construct loaded substantially higher with one another, exceeding the common threshold of .60, and higher than loadings with items that measure different constructs [51]. We further examined the measurement model. As shown in Table 3, all investigated constructs had a composite reliability greater than .50, a common threshold that signifies adequate reliability [52]; the value of the average variance extracted (AVE) for each construct also exceeds the common threshold of .60 [53]. Together, these results suggest that the items possess appropriate construct validity, and convergent and discriminant validity.

Table 2. Summary of cross-factor loadings

\begin{tabular}{|l|l|l|l|l|l|}
\hline & SI & GS & EA & ENAB & ENRI \\
\hline SI -1 & $\mathbf{0 . 8 9 5}$ & 0.242 & 0.149 & 0.204 & 0.079 \\
\hline SI -2 & $\mathbf{0 . 8 8 9}$ & 0.280 & 0.152 & 0.162 & -0.002 \\
\hline SI -3 & $\mathbf{0 . 8 2 0}$ & 0.346 & 0.253 & 0.144 & -0.032 \\
\hline GS-1 & 0.290 & $\mathbf{0 . 8 4 5}$ & 0.214 & 0.056 & 0.019 \\
\hline GS-2 & 0.226 & $\mathbf{0 . 8 4 4}$ & 0.128 & 0.172 & 0.059 \\
\hline GS-3 & 0.250 & $\mathbf{0 . 8 0 3}$ & 0.081 & 0.107 & 0.128 \\
\hline EA-1 & 0.205 & 0.014 & $\mathbf{0 . 7 8 7}$ & 0.162 & 0.224 \\
\hline EA-2 & 0.137 & 0.215 & $\mathbf{0 . 6 7 4}$ & 0.199 & 0.213 \\
\hline EA-3 & 0.181 & 0.421 & $\mathbf{0 . 6 5 2}$ & 0.232 & 0.044 \\
\hline ENAB-1 & 0.115 & 0.108 & 0.342 & $\mathbf{0 . 8 3 3}$ & 0.186 \\
\hline ENAB-2 & 0.298 & 0.259 & 0.038 & $\mathbf{0 . 7 5 5}$ & 0.097 \\
\hline ENAB-3 & 0.132 & 0.011 & 0.430 & $\mathbf{0 . 6 6 0}$ & 0.332 \\
\hline ENRI-1 & 0.005 & 0.085 & 0.179 & 0.170 & $\mathbf{0 . 9 0 8}$ \\
\hline ENRI-2 & 0.014 & 0.077 & 0.201 & 0.175 & $\mathbf{0 . 8 9 2}$ \\
\hline
\end{tabular}

Note. SI: Stickiness intention; EA: Emotional attachment; GS: Gratifying the self; ENRI: Enriching the self; ENAB: Enabling the self

\subsection{Hypotheses test results}

Similar to multiple regression, the quality of Partial Least Squares (PLS) models are evaluated based on the direction and significance of path coefficients, and the magnitude of $\mathrm{R}^{2}$, which signifies the amount of variance that is explained by the model. We specified a structural model in PLS and ran the PLS algorithm as well as the bootstrapping procedure to obtain path coefficients, their respective t-values, and $R^{2}$ coefficients of the endogenous constructs. While there is no generally acceptable threshold for the value of $\mathrm{R}^{2}$, some experts suggest a value of .20 is considered high enough in consumer behavior studies. Our results are shown in Figure 2.

In line with Hypothesis H1 is strongly supported: gratifying the self has positive effects on emotional attachment, and the effect of enriching the self on emotional attachment (H2) is significant. In addition, Hypothesis H3 is strongly supported, which means enabling the self has positive effects on emotional attachment. Thus, $\mathrm{H} 1, \mathrm{H} 2$ and $\mathrm{H} 3$ are supported. Overall, the explained variance in emotional attachment accounted for by gratifying the self, enriching the self and enabling the self is $R^{2}$ $=.49$. In addition, Hypothesis 4, emotional attachment positively impacts users' stickiness intention. As shown in Figure 2, the model exhibits adequate explanatory power, accounting for $25 \%$ of the variance in behavioral engagement (refer to Table 4 for $\beta$ coefficients and t-values).

Table 3. Correlations and constructs

\begin{tabular}{|c|c|c|c|c|c|c|c|c|c|}
\hline Construct & $\mathbf{M}$ & SD & CA & CR & 1 & 2 & 3 & 4 & 5 \\
\hline 1. GS & 3.50 & 0.74 & 0.87 & 0.69 & $(0.83)^{\mathrm{a}}$ & & & & \\
\hline 2. ENRI & 2.51 & 1.00 & 0.90 & 0.81 . & $.20^{*}$ & $(0.90)$ & & & \\
\hline 3. ENAB & 2.93 & 0.86 & 0.80 & 0.57 . & $.38 * *$ & $46 * *$ & $(0.75)$ & & \\
\hline 4. EA & 2.91 & 0.82 & 0.75 & 0.50 . & $.47 * *$ & $.44 * *$ & $.62 * *$ & $(0.71)$ & \\
\hline 5. SI & 3.16 & 1.04 & 0.90 & 0.75 . & $.59 * *$ & .12 & $.46 * *$ & $.49 * *$ & $(0.87)$ \\
\hline \multicolumn{10}{|c|}{$\begin{array}{l}\text { Note. } \mathrm{M}=\text { mean; } \mathrm{SD}=\text { standard deviation; } \mathrm{CA}=\text { Cronbach's } \alpha ; \mathrm{CR} \\
=\text { composite reliability; }{ }^{\mathrm{a}} \text { Diagonal element indicates the square root } \\
\text { of AVE. }\end{array}$} \\
\hline
\end{tabular}

Table 4. Hypotheses Testing - Path Analyses ( $\beta, t$-Value)

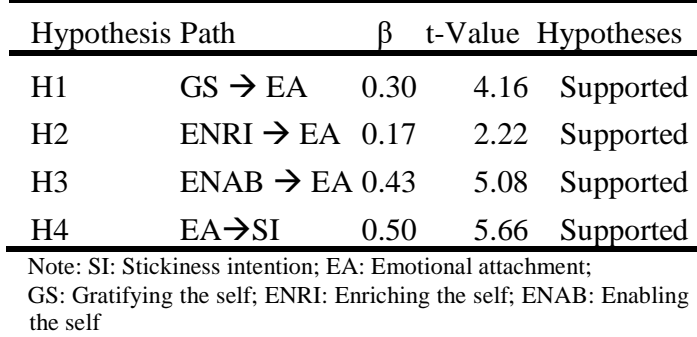




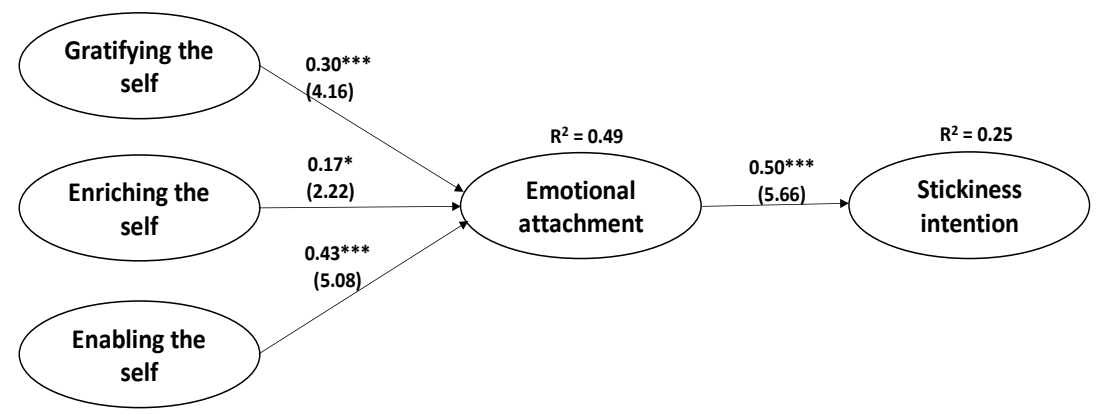

Figure 2. Model and Hypothesis Test Results

\subsection{Mediation test}

To assess whether mediation was present in the general theoretical model, the significance of the indirect effects of GS, ENRI and ENAB on SI through EA was tested using the bias-corrected bootstrap confidence intervals (CIs). Bootstrapping is a nonparametric resampling method that can be extended to designs involving indirect effects. To bootstrap the sampling distribution of the indirect effects, the regression coefficients are repeatedly estimated $k$ times with bootstrap samples, each of contains $n$ cases randomly sampled with replacement from the original sample (that is a given case can be selected multiple times), where $n$ is the size of the original sample. This process yields $k$ estimates of the indirect effects of the independent variable (GS, ENRI and ENAB) on the dependent variable (SI). These $k$ values of the indirect effects are then sorted from low to high, thus enabling the specification of the lower and upper bounds of the desired CI. MacKinnon, Lockwood, and Williams [54] conducted simulation studies to examine the accuracy of various tests on mediation effects, and advocated the bias-corrected approach as the best way to test indirect paths in mediation analysis, when normality assumptions appear to be violated. The bias-corrected bootstrap was conducted in SPSS using PROCESS computational tool [55], generating 10,000 bootstrap samples and 95\% bias-corrected CIs for indirect effects. Since the percentile bootstrap CIs can be asymmetrical because they are based on an empirical estimation of the sampling distribution of the indirect effect, a correction is applied to the percentile values of the sorted distribution of bootstrap estimates used for determining the bounds of the interval. Hence the term "bias-corrected" is derived from this adjustment made to the percentile values so that the CIs are equidistant from the point estimate. In the model, the indirect effect GS exerted through EA was equal to $\beta=.175$, $\mathrm{GS}=.077(95 \% \mathrm{CI}=.031, .330)$, ENRI exerted through EA was equal to $\beta=.246$, ENRI $=.067$
(95\% $\mathrm{CI}=.130, .386)$, and ENAB exerted through $\mathrm{EA}$ was equal to $\beta=.241, \mathrm{ENAB}=.097$ $(95 \% \mathrm{CI}=.051, .433)$. These led to the rejection of the null hypothesis that the indirect effect was zero, given that the corresponding 95\% CI did not contain zero. EA did mediate the effect of GS, ENRI and ENAB on SI; therefore, hypothesis $5 \mathrm{a}-\mathrm{c}$ were supported.

\section{Discussion and conclusion}

In theoretical aspect, the majority of studies related to live streaming focus on the computer science, such as peer to peer transmission and workload. Thus, this research enriches the studies of live streaming in the aspect of consumer behavior, in the field of social science. Previous studies implied attachment theory initially in relationship between kid and parents, then in relationship between consumer and good, service even brand. In this study, live streaming can be approximately regarded as service but it is quite different with traditional service on account of its highly interactivity, real-time and the background of virtual communication. Thus, this article extends attachment theory to a new context, live streaming, which fills the empty of implication of attachment theory in this area.

In the aspect of implication, the enhancement of user stickiness is the key to the continuous development of the live streaming platform. Based on the theory of attachment, from a new perspective of users' stickiness, this article provides theoretical support for operators of live streaming platforms to enhance the emotional attachment of users, rather than only focus on advertisement to get attention. Additionally, platforms operators and internet celebrities should pay close attention to the feedback of users, particularly bullet screen, which may reflect mental activity like attachment and can help to strengthen users' stickiness.

In this research, all the hypotheses were tested comprehensively and results were analyzed. However, it is unavoidable that this study has its limitations. First, the perception of 
emotion is different between countries and cultures, which may influence the effectiveness of the measuring scale. Second, we didn't consider the differences between types of live streaming platform, because users may focus on gratifying the self when attach the live streaming platforms which are providing entertainment, but users who focus on education and technology might prefer enriching the self.

Finally, future research can investigate how extended-self and emotional attachment influence different users' behaviors. For example, in live streaming, in addition to watching and interacting with internet celebrities by bullet screen, users can purchase virtual gifts to their favorite internet celebrity as tips. Moreover, the virtual community and interpersonal relationship can be considered as the antecedent variables in future research.

\section{References}

[1] Rodriguez-Gil, L. et al. (2017). Interactive livestreaming technologies and approaches for web-based applications. Multimedia Tools and Applications, 1-32.

[2] Tran, H. T. T., Won, Y., \& Kim, J. (2017). An efficient hybrid push-pull methodology for peer-to-peer video live streaming system on mobile broadcasting social media. Multimedia Tools and Applications, 76(2), 2557-2568.

[3] Sanderson, J. (2011). To tweet or not to tweet: Exploring Division I athletic departments' social-media policies. International Journal of Sport Communication, 4(4), 492-513.

[4] Kim, J., \& Song, H. (2016). Celebrity's selfdisclosure on Twitter and parasocial relationships: A mediating role of social presence. Computers in Human Behavior, 62, 570-577.

[5] Payne, K. et al. (2017). Examining the learning effects of live streaming video game instruction over Twitch. Computers in Human Behavior, 77, 95-109.

[6] Thomson, M. (2006). Human brands: Investigating antecedents to consumers' strong attachments to celebrities. Journal of marketing, 70(3), 104-119.

[7] Greenwald, A. G., \& Pratkanis, A. R. (1984). The sell in RS Wyer, \& TK Srull. Handbook of social cognition, 129-178.

[8] Park, C. W., MacInnis, D. J., \& Priester, J. R. (2006). Beyond attitudes: Attachment and consumer behavior.

[9] Bowlby, J. M. (1969). Attachment and loss, 1(4), 595-599.

[10] Marvin, R. S., \& Pianta, R. C. (1996). Mothers' reactions to their child's diagnosis: Relations with security of attachment. Journal of Clinical Child Psychology, 25(4), 436-445.

[11] Lopez, F. G. (1995). Contemporary attachment theory: An introduction with implications for counseling psychology. The Counseling Psychologist, 23(3), 395-415.

[12] Dwayne Ball, A., \& Tasaki, L. H. (1992). The role and measurement of attachment in consumer behavior. Journal of consumer psychology, 1(2), 155-172.

[13] Yuksel, A., Yuksel, F., \& Bilim, Y. (2010). Destination attachment: Effects on customer satisfaction and cognitive, affective and conative loyalty. Tourism management, 31(2), 274-284.

[14] Whan Park, C. et al. (2010). Brand attachment and brand attitude strength: Conceptual and empirical differentiation of two critical brand equity drivers. Journal of marketing, 74(6), 117.

[15] Ren, Y. et al. (2012). Building member attachment in online communities: Applying theories of group identity and interpersonal bonds. MIS Quarterly, 841-864.

[16] Belk, R. W. (1988). Possessions and the extended self. Journal of consumer research, 15(2), 139-168.

[17] Sivadas, E., \& Venkatesh, R. (1995). An examination of individual and object-specific influences on the extended self and its relation to attachment and satisfaction. ACR North American Advances.

[18] Hamilton, K., \& Hassan, L. (2010). Selfconcept, emotions and consumer coping: smoking across Europe. European Journal of Marketing, 44(7/8), 1101-1120.

[19] Aron, A., Aron, E. N., \& Smollan, D. (1992). Inclusion of other in the self scale and the structure of interpersonal closeness. Journal of personality and social psychology, 63(4), 596.

[20] Mikulincer, M. (1998). Attachment working models and the sense of trust: An exploration of interaction goals and affect regulation. Journal of personality and social psychology, 74(5), 1209.

[21] Bolter, J. D. (1996). Virtual reality and the redefinition of self. Communication and cyberspace: Social interaction in an electronic environment, 105-20.

[22] Belk, R. W. (2013). Extended self in a digital world. Journal of Consumer Research, 40(3), 477-500.

[23] Mao, Y. et al. (2016). Optimal Experience and Optimal Identity: A Multinational Study of the Associations Between Flow and Social Identity. Frontiers in Psychology, 7, 67.

[24] Davenport, T.H (2000). Sticky business. CIO, 13(8), 58-60.

[25] Oliver, R. L. (1999). Whence consumer loyalty? the Journal of Marketing, 33-44.

[26] Lin, J. C. C. (2007). Online stickiness: its antecedents and effect on purchasing intention. Behaviour \& information technology, 26(6), 507-516.

[27] Gefen, D., Karahanna, E., \& Straub, D. W. (2003). Trust and tam in online shopping: an integrated model. MIS Quarterly, 27(1), 51-90.

[28] Agarwal, R., \& Karahanna, E. (2000). Time flies when you're having fun: Cognitive absorption and beliefs about information technology usage. MIS quarterly, 665-694. 
[29] Slater, J. S. (2000, October). Collecting brand loyalty: A comparative analysis of how CocaCola and Hallmark use collecting behavior to enhance brand loyalty. Paper presented at the Annual Conference of the Association of Consumer Research, Salt Lake City, UT.

[30] Hill, R. P., \& Stamey, M. (1990). The homeless in America: an examination of possessions and consumption behaviors. Journal of Consumer Research, 17(3), 303-321.

[31] Schouten, J. W., \& Mcalexander, J. H. (1995). Subcultures of consumption: an ethnography of the new bikers. Journal of Consumer Research, 22(1), 43-61.

[32] Richins, M. L. (1994). Special possessions and the expression of material values. Journal of consumer research, 21(3), 522-533.

[33] O'Guinn, T. C. (1991). Touching greatness: The central midwest Barry Manilow fan club. ACR Special Volumes.

[34] Hu, M., Zhang, M., \& Wang, Y. (2017). Why do audiences choose to keep watching on live video streaming platforms? An explanation of dual identification framework. Computers in Human Behavior, 75, 594-606.

[35] Bartels, A., \& Zeki, S. (2004). The chronoarchitecture of the human brain: functional anatomy based on natural brain dynamics and the principle of functional independence. Elsevier.

[36] Chaudhuri, A., \& Holbrook, M. B. (2001). The chain of effects from brand trust and brand affect to brand performance: the role of brand loyalty. Journal of marketing, 65(2), 81-93.

[37] Carroll, B. A., \& Ahuvia, A. C. (2006). Some antecedents and outcomes of brand love. Marketing Letters, 17(2), 79-89.

[38] Greenwald, A. G., \& Breckler, S. J. (1986). Motivational facets of the self. Handbook of motivation and cognition: Foundations of social behavior, 145-164.

[39] Markus, H., \& Nurius, P. (1986). Possible selves. American psychologist, 41(9), 954.

[40] Wallendorf, M., \& Arnould, E. J. (1988). "My favorite things": A cross-cultural inquiry into object attachment, possessiveness, and social linkage. Journal of Consumer Research, 14(4), 531-547.

[41] Fournier, S. (1998). Consumers and their brands: Developing relationship theory in consumer research. Journal of consumer research, 24(4), 343-373.

[42] Kleine, S. S., \& Baker, S. M. (2004). An integrative review of material possession attachment. Academy of Marketing Science Review, 23(1), 4-41.

[43] Funk, D. C., \& James, J. D. (2006). Consumer loyalty: the meaning of attachment in the development of sport team allegiance. Journal of Applied Physiology, 105(2), 621-8.

[44] Lee, J., Kyle, G., \& Scott, D. (2012). The mediating effect of place attachment on the relationship between festival satisfaction and loyalty to the festival hosting destination. Journal of Travel Research, 51(6), 754-767.

[45] Zott, C., Amit, R., \& Donlevy, J. (2000). Strategies for value creation in e-commerce: best practice in Europe. European Management Journal, 18(5), 463-475.

[46] Khalifa, M., Limayem, M., \& Liu, V. (2002). Online customer stickiness: a longitudinal study. Journal of Global Information Management (JGIM), 10(3), 1-14.

[47] Mathwick, C. (2002). Understanding the online consumer: a typology of online relational norms and behavior. Journal of Interactive Marketing, 16(1), 40-55.

[48] Vlachos, P. A., Theotokis, A., Pramatari, K., \& Vrechopoulos, A. (2010). Consumer- retailer emotional attachment: some antecedents and the moderating role of attachment anxiety. European Journal of Marketing, 44(9/10), 1478-1499.

[49] Li, D., Browne, G. J., \& Wetherbe, J. C. (2006) Why do internet users stick with a specific web site? a relationship perspective. International Journal of Electronic Commerce, 10(4), 105141.

[50] Nunnally, J.C. (1978). Psychometric theory. McGraw-Hill, New York.

[51] Hair, J. E. et al. (2006). Multivariate Data Analysis. Upper Saddle River, New Jersey: Pearson-Prentice Hall.

[52] Bagozzi, R. \& Yi, Y. (2012). Specification, evaluation, and interpretation of structural equation models. Journal of the Academy of Marketing Science, 40(1), 8-34.

[53] Bagozzi, R. P. \& Yi, Y. (1988). On the evaluation of structural equation models. Journal of the Academy of Marketing Science, 16(Spring), 74-94.

[54] Mackinnon, D. P., Lockwood, C. M., \& Williams, J. (2004). Confidence limits for the indirect effect: distribution of the product and resampling methods. Multivariate Behavioral Research, 39(1), 99-128.

[55] Hayes, A.F. (2012). PROCESS: A versatile computational tool for observed variable mediation, moderation, and conditional process modeling.

[56] Chen, D. (2017, May 2). Live Streaming in China: The Top 5 Platforms [Web Blog Message]. Retrieved from https://chozan.co/category/chinese-consumerbehavior/

[57] James, W. (1992). Writings 1878-1899. New York: The Library of America.

[58] Baumeister, R. F. (Ed.) (1999). The self in social psychology. Philadelphia, PA: Psychology Press (Taylor \& Francis).

[59] Scheibe, K., Fietkiewicz, K. J., \& Stock, W.G. (2016). Information Behavior on Social Live Streaming Services. Journal of Information Science Theory and Practice, 4(2), 06-20.

[60] Pires, K., \& Simon, G. (2015). Youtube live and twitch:a tour of user-generated live streaming systems. MMSys '15 Proceedings of the 6th ACM Multimedia Systems, 225-230.

[61] Zhao, J., Ma, M., Gong, W., Zhang, L., Zhu, Y., \& Liu, J. (2017). Social media stickiness in Mobile Personal Livestreaming service. In 2017 IEEE/ACM 25th International Symposium on Quality of Service (IWQoS). 